\title{
Biomechanics of the immediate impact of wearing a rigid thoracolumbar corset on gait kinematics and spatiotemporal parameters
}

\author{
Redha Taiar ${ }^{l,}$, , Alexandra Mitton ${ }^{2}$, Julien Cambier ${ }^{1}$, Islem Guenaoui ${ }^{1}$, Sophie Michel ${ }^{3}$, \\ Ellie Abdi ${ }^{4}$, and Guillaume Polidori ${ }^{1}$ \\ ${ }^{1}$ Research Group in Engineering Sciences (GRESPI), University of Reims, France \\ ${ }^{2}$ Masseur Kinésithérapeute, Doulaincourt Saucourt, France \\ ${ }^{3}$ Institut de Formation en Masso-Kinésithérapie (IFMK), Reims, France \\ ${ }^{4}$ Montclair State University, New Jersey, USA
}

\begin{abstract}
The corset support is a device classified as orthosis. It compensates a functional deficiency with means of protection, recovery, correction, maintenance, and support or contention. There are two types of orthosis 1) rest orthosis and 2) corrective orthosis. Rest orthosis maintains joints in a defined position to avoid deformities or to relieve a pain at joints. Corrective orthosis adjusts joint deformity either passively or actively. Corset is used in various pathological use, thoracic-lumbar fracture, scoliosis, Scheuermann's disease or spinal dystrophy. The purpose of this study was 1) to determine the immediate impact of wearing a semi-rigid thoracolumbar corset, the Lombax ${ }^{\circledR}$ Dorso on gait kinematics and 2) spatiotemporal parameters in 6 adults. These parameters were recorded using the optoelectronic system Vicon ${ }^{\circledR}$ on treadmill gait subjects with and without corset for the comparison. The results showed that wearing a corset significantly decrease the rotation amplitudes of the scapular and pelvic girdles $(\mathrm{p}<0.05)$ in the frontal plane. The movement of the pelvis and hip in this same plane was decreased also when comparing with and without a corset effects $(p<0.05)$. The corset significantly increased the range of flexion-extension of the hip during the gait cycle. At the conclusion of this study the discriminate parameters of wearing a corset was quantified. The results and in association with manufacturer will help to improve materials for better optimization support. Comparable perspectives and after improvement of materials will aim to experiment with patients on real daily life situation.
\end{abstract}

\section{Introduction}

The purpose of this study was to determine immediate impact of wearing a semi-rigid thoracolumbar corset, the Lombax ${ }^{\circledR}$ Dorso on gait kinematics and spatiotemporal parameters in 6 healthy adults. The corset is an apparatus classified as orthosis. It

\footnotetext{
*Corresponding author: redha.taiar@univ-reims.fr
} 
compensate for a functional deficiency with means of protection, recovery, correction, maintenance, and support or contention [1]. There are several categories of orthoses depending on the searched purpose. The corsets were comprised of two types, 1) rest orthosis and 2) corrective orthosis. Rest orthosis maintains joints in a defined position to avoid deformities or to relieve a pain at joints. Corrective orthosis corrects joint deformity either passively or actively. Corsets are used in various pathological aspects, thoracolumbar fracture [2-4], scoliosis [5], Scheuermann's disease or spinal dystrophy [6]. By its application, a corset limits the movement of several joints therefore; a corset could impede walking and increase its energy costs. It is noteworthy to evaluate effects of wearing a corset on gait spatiotemporals and kinematics parameters in order to collect elements to be worked during its removal.

Gait is sequenced in cycle beginning with the contact of one foot on the ground and ending with the next contact of this same foot. It alternates a support phase where the foot stays on the ground and an oscillating phase where the foot is not in contact with the ground [7-9]. Technological advances made it possible to develop new tools allowing a fine analysis of gait. It provided quantitative and objectives data. In this study, an optoelectonic system has been chosen for the measurements. Various studies on impact of wearing a corset on gait and kinematics parameters have been investigated [10-13]. The trends obtained in this study were validated.

\section{Materials and methods}

Six subjects (4 women's and 2 men's) participated in this study with $21 \pm 1,5$ Age, $60 \pm 5$ $\mathrm{kg}$ and $171 \pm 6,5 \mathrm{~cm}$ size. The criteria of inclusion are the absence of old traumas, orthopedic disorders at the musculoskeletal system and rachis. Before the realization of the experiment, they were informed by modalities of the experimentation and gave by writing their informed consent.

The Lombax ${ }^{\circledR}$ Dorso, a corset of the Thuasne ${ }^{\circledR}$ brand (Fig.1), was used in this study. It is indicated in muscular and static insufficiencies, osteoporosis (vertebral compression fracture) and postoperative maintain. Depending on the manufacturer [14], the corset acts by a 3-point support of the recovery and stabilization of the thoracic spine. This is possible by the recoil of scapular belt, 1) on the discharge of the thoracic and lumbar vertebral corpus and 2) on the increased intra-abdominal pressure.

A treadmill was used to give a constant gait speed to the subjects. A $480 \mathrm{CX}$ treadmill model of Proform ${ }^{\circledR}$ was utilized. In a study Stoquart, Detrembleur, and Lejeune [15] have shown that gait kinematics and spatiotemporals parameters were dependent of the speed. It is therefore necessary to develop a constant gait speed in order to avoid a bias. Several studies [15-18] concluded that the recorded parameters during gait on the treadmill were similar to those of gait on the ground.

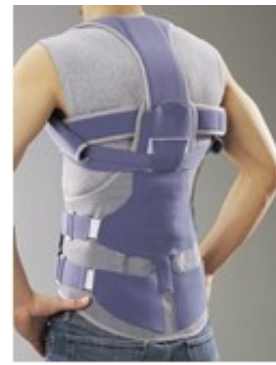

Fig. 1. Lombax ${ }^{\circledR}$ Dorso corset of the brand Thuasne ${ }^{\circledR}[24]$

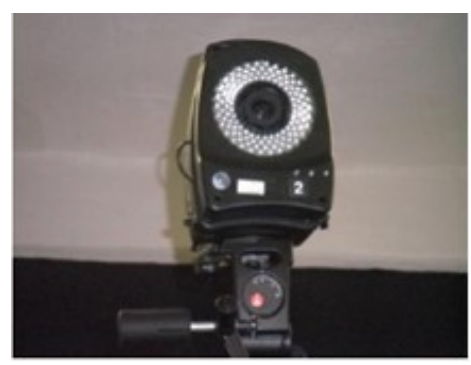

Fig. 2. Camera of Vicon ${ }^{\circledR}$ optoelectronic system 
The Vicon ${ }^{\circledR}$ optoelectonic system was used to measure gait kinematics and spatiotemporal data. It was composed of 5 cameras (Fig.2) which produced infrared light. The subject was equipped with markers that reflected this infrared light. This allowed the cameras to capture and to record the markers' trajectory in the 3 dimensions with an accuracy order of a millimeter. Cameras were connected to a digital recorder (Oxford Metrics Vicon ${ }^{\circledR}$ Data station 3D motion capture interface). This digital recorder was connected to a central processing unit. Eighteen markers infrared light reflectors with a diameter of $14 \mathrm{~mm}$ were placed on the subjects to calculate the joints centers.

The experimental protocol was itemized into 9 steps:

1. Arranging the acquisition volume around the treadmill (Fig.3).

2. System calibration.

3. Placement of 18 reflective markers at $14 \mathrm{~mm}$ in diameter on the level of the lower limbs and the scapular belt (Fig.4). These are placed on anatomical point defined by the Plugin-Gait model.

4. Measurement of anthropometrics parameters of each subject essential for the calculation of the joints centers.

5. Walking at $4 \mathrm{~km} / \mathrm{h}$ for 3 minutes by the subject in order for familiarization with the treadmill to eliminate leaning bias.

6. Recording of kinematics and spatiotemporal data by the Vicon ${ }^{\circledR}$ optoelectronic system with a sampling frequency of $120 \mathrm{~Hz}$. Three 30 -seconds tests were performed during which the subject was asked to walk at $4 \mathrm{~km} / \mathrm{h}$ while looking straight (Fig.5-a). In between each trial, the subject continued to walk.

7. Placement of Lombax ${ }^{\circledR}$ Dorso corset.

8. Recording of gait kinematics and spatiotemporal data with wearing of corset (Fig.5-b).

9. Data processing was filtered to eliminate noise. A biomechanical model OLGA (Optimized Lower-Limb Gait Analysis) was applied to calculate the joints centers by the positions of the markers combined with the anthropometrics parameters of the subject.

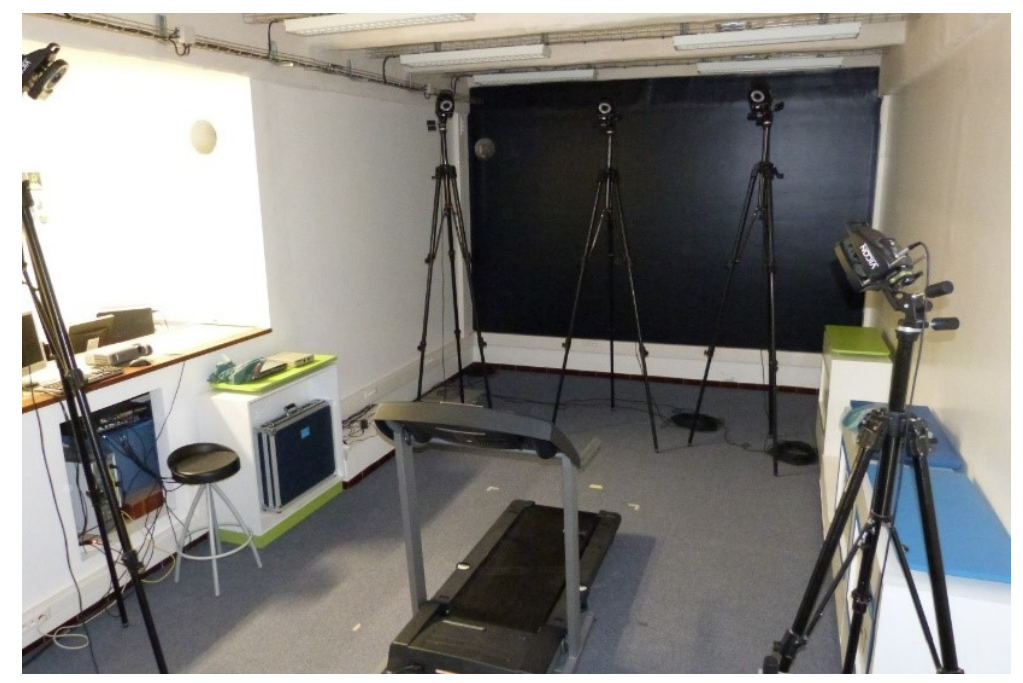

Fig. 3. Acquisition volume 


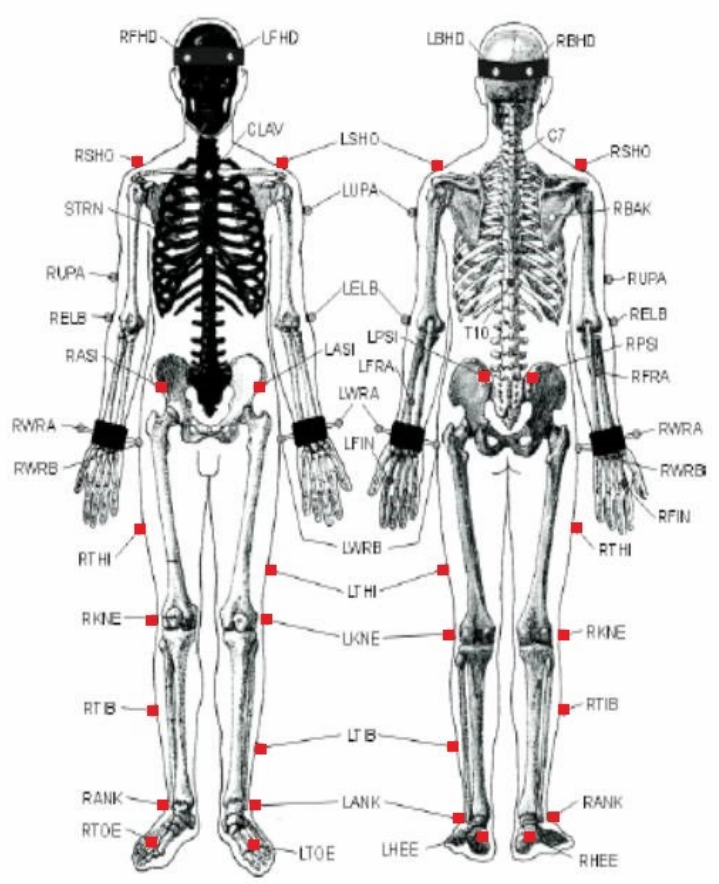

Fig. 4. Plug-in-Gait model [34]
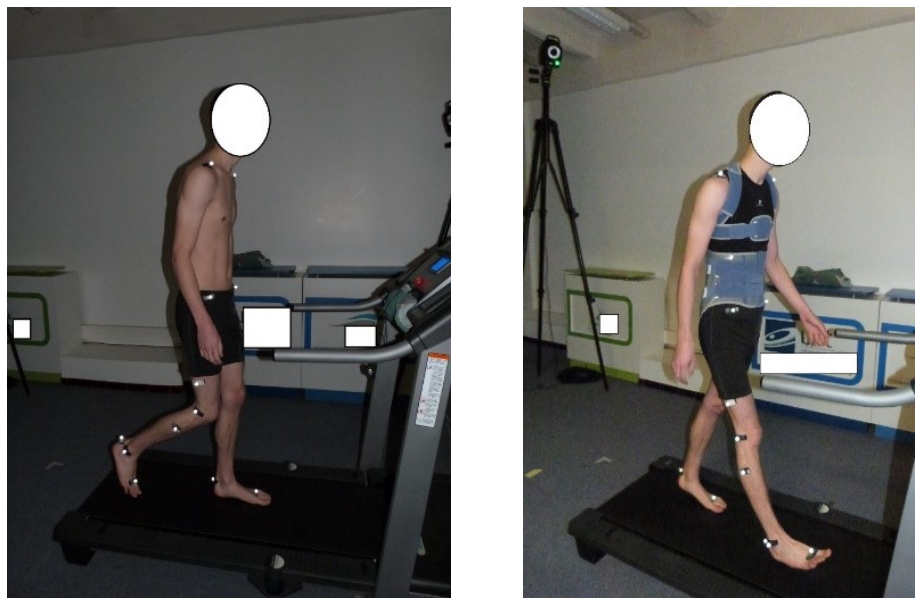

Fig. 5. Gait without (a) and with (b) corset at $4 \mathrm{~km} / \mathrm{h}$

\section{Results and discussion}

The results obtained for gait without a corset and gait with Lombax ${ }^{\circledR}$ Dorso corset on a treadmill at $4 \mathrm{~km} / \mathrm{h}$ were compared (Table 1 and Fig. 6).

It is observable that wearing of the Lombax ${ }^{\circledR}$ Dorso corset has little effect on the spatial parameters analyzed (Step Length (ST) and duration of the support phase (DSP)) during a gait at $4 \mathrm{~km} / \mathrm{h}$, deviations not exceeding $3 \%$ in this study. Results on kinematics parameters at the scapular belt, pelvis, hip, knee, and ankle were more significant. At the level of 
scapular belt, the amplitude of rotation decreased by $41.25 \%$ when corset was worn during gait. This decrease of $6^{\circ}$ is significant, which confirms the hypothesis that this movement is limited due to the application of the corset in three points (sternal, spinal and pelvis). At the level of the pelvis in transverse plane, a significant difference was noted. The amplitude of pelvis rotation decreased by $30 \%$ between the two experimental conditions. The hypothesis which during the physiological gait, there was a dissociation of the scapular and pelvic belts thus was confirmed.

Table 1: Comparison of saptiotemporal and kinematic parameters between gait conditions with and without corset.

\begin{tabular}{|c|c|c|c|c|}
\hline & \multicolumn{2}{|c|}{ Average and standard deviation } & \multirow{2}{*}{ Difference } & \multirow{2}{*}{ Variation $\%$} \\
\hline & Without corset & With corset & & \\
\hline Step Length SL (m) & $0,66 \pm 0,05$ & $0,66 \pm 0,06$ & 0 & 0,55 \\
\hline $\begin{array}{l}\text { Duration of Support phase DSP } \\
\text { (s) }\end{array}$ & $0,43 \pm 0,05$ & $0,44 \pm 0,06$ & 0,01 & 2,24 \\
\hline $\begin{array}{l}\text { Scapular belt - Transverse plane } \\
\text { SBTP }\left({ }^{\circ}\right)\end{array}$ & $14,15 \pm 4,71$ & $8,31 \pm 2,64$ & $-5,84$ & $-41,25$ \\
\hline $\begin{array}{l}\text { Pelvis - } \\
\text { Transverse plane PTP }\left(^{\circ}\right)\end{array}$ & $9,03 \pm 4,73$ & $6,26 \pm 2,12$ & $-2,78$ & $-30,74$ \\
\hline $\begin{array}{l}\text { Pelvis - } \\
\text { Frontal plane PFP }\left(^{\circ}\right)\end{array}$ & $9,10 \pm 2,62$ & $5,76 \pm 2,97$ & $-3,34$ & $-36,7$ \\
\hline $\begin{array}{l}\text { Hip - } \\
\text { Sagittal plane } \operatorname{HSP}\left({ }^{\circ}\right)\end{array}$ & $40,33 \pm 3,33$ & $42,91 \pm 4,45$ & 2,57 & 6,38 \\
\hline $\begin{array}{l}\text { Hip - } \\
\text { Frontal plane HFP }\left({ }^{\circ}\right)\end{array}$ & $11,37 \pm 2,28$ & $8,5 \pm 2,45$ & $-2,86$ & $-25,19$ \\
\hline $\begin{array}{l}\text { Knee - } \\
\text { Sagittal plane KSP }\left(^{\circ}\right)\end{array}$ & $56,72 \pm 3,90$ & $58,16 \pm 3,98$ & 1,44 & 2,53 \\
\hline $\begin{array}{l}\text { Ankle - } \\
\text { Sagittal plane ASP }\left(^{\circ}\right)\end{array}$ & $29,47 \pm 10,19$ & $31,52 \pm 10,71$ & 2,05 & 6,95 \\
\hline
\end{tabular}

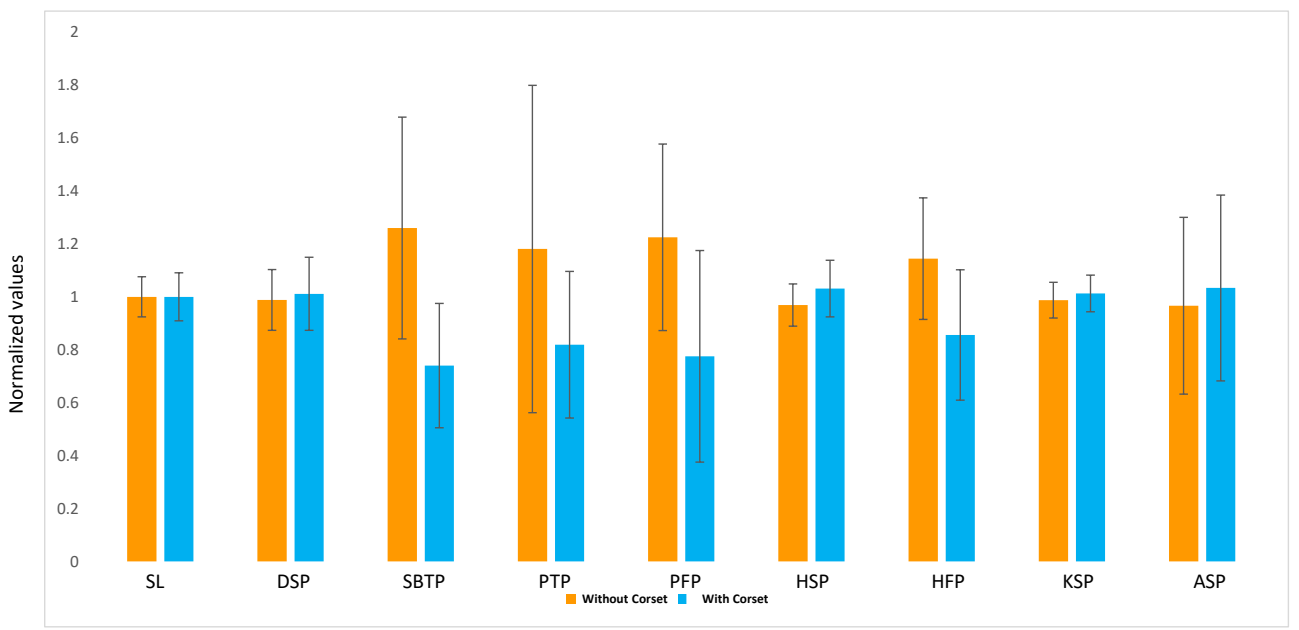

Fig. 6. Comparison of parameters without and with corset (values normalized: division by the average). 
In the literature, the results diverge according to the studies. In the study of Mahaudens, Banse, and Detrembleur [10] along with Vogt, Pfeifer, Portscher, and Banzer [13] thermoformed rigid corset had no significant influence on this movement of the pelvis during gait. In addition, the experimentation of Konz, Fatone, and Gard [12] also shows that wearing a fiberglass corset significantly reduces the rotation of the pelvis during gait. In the frontal plane of the pelvis, all studies [10,12, and 13] are in agreement with this study. A significant decrease in the amplitude of the pelvis in the frontal plane either for a thermoformed rigid corset, fiberglass or for a lumbar corset was found. At the level of the hip in the sagittal plane, while wearing the semi-rigid corset increased by approximately $6 \%$ amplitude of flexion-extension during the gait. This confirmed the hypothesis adopted beforehand.

The speed of walking was imposed at $4 \mathrm{~km} / \mathrm{h}$. With the intention of maintaining this rhythm, the amplitude of flexion-extension of the hip increased in order to compensate for the movements limited by the corset. The length of the step was not affected by the modification of these kinematic parameters which Konz et al., [12] confirmed as a found result. In the frontal plane of the hip, while the Lombax ${ }^{\circledR}$ Dorso corset was worn it resulted in a significant decrease in the amplitude of the adduction-abduction movements. Thus, the worn corset limiting the movement of the pelvis in the frontal plane led to a reduction in the amplitude. This reduction was observed at the adduction-abduction of the hip during walking, a result also noticed in $[10,12]$. Concerning the influence on the knee and the ankle this study respected that there was no significant evolution yet again confirmed by [12].

\section{Conclusion}

This study was attentive in immediate impact of worn rigid thoracolumbar corset, the Lombax ${ }^{\circledR}$ Dorso, on gait kinematics and spatiotemporal parameters in 6 healthy adults. It followed those amplitudes of the rotations scapular and pelvic belts of the inclination of the pelvis in the frontal plane. In addition adduction-abduction of the hip which were significantly diminished by wearing the corset while amplitude of flexion-extension of hip increased significantly for the study population. For the latter, the results obtained made it possible to establish rehabilitation objectives and to propose physiotherapy methods in order to recover a physiological march.

\section{Acknowledgement}

The authors declare that there was no personal financial interest in conducting this research. The information on companies' names is integral to the research.

\section{References}

1. Y. Xhardez et collaborateurs, Vade-mecum de kinésithérapie et de rééducation fonctionnelle, 6e édition (Maloine, Paris, 2009), pp 96-97.

2. J. C. Dosch, Traumatologie du rachis. Issy-les-Moulineaux (Elsevier, Masson, 2012) p.103.

3. M. Freslon, D. Bouaka, P. Coipeau, G. Defossez, N. Leclercq, J. Nebout, E. Marteau, N. Poilbout, R. Prebet, Revue de chirurgie orthopédique et réparatrice de l'appareil locomoteur 94S, S22-S35 (2008).

4. P. Guigui, B. Lassale, A. Deburge, Fractures et luxations récentes du rachis dorsal et lombaire de l'adulte (EMC, 15-829-A-10, 1998).

5. A. V. Bruyneel, P. Chavet, S. Mesure, Kinésithérapie la revue 8, 23-29 (2008). 
6. C. Palazzo, F. Sailhan, M. Revel, Revue de rhumatisme monographies 81, 7-15 (2014).

7. P. A. Willems, B. Schepens, C. Detrembleur, Marche normale (EMC, 26-007-B-75, 2012).

8. S. Armand. Analyse Quantifiée de la Marche : extraction de connaissances à partir de données pour l'aide à l'interprétation clinique de la marche digitigrade, Thèse présentée à l'Université de Valenciennes et du Hainaut Cambrésis. Numéro d'ordre 0507 (2005).

9. Viel E et collaborateurs, La marche humaine, la course et le saut: biomécanique, explorations, normes et dysfonctionnements (Masson, Paris, 2000) p.18.

10. P. Mahaudens, X. Banse, C. Detrembleur, Gait \& Posture 28, 703-707 (2008).

11. M. S. Wong, C. Y. Cheng, B. K. W Ng, Gait \& Posture 28, 189-195 (2008).

12. R. Konz, S. Fatone, S. Gard, J. Rehabil. Res. Dev. 43, 161-170 (2006).

13. L. Vogt, K. Pfeifer, W. Portscher, W. Banzer, J. Rehabil. Res. Dev. 37, 495-499 (2000).

14. W. H. Wu, X. C. Lin, O. G. Meijer et al., Human Movement Science 33, 194-202 (2014).

15. G. Stoquart, C. Detrembleur, T. Lejeune, Clinical Neurophysiology, 38, 105-116 (2008).

16. O. P. Riley, G. Paolini, U. Della Croce, K.W. Paylo, D.C. Kerrigan, Gait \& Posture 26, 17-24 (2006).

17. K. Parvataneni, L. Ploeg, S. J. Olney, B. Brouwer, Clinical Biomechanics 24, 95-100 (2009).

18. D. Pradon, E. Hutin, S. Khadir, R. Taiar, F. Genet, N. Roche, Clinical Biomechanics 26, 867-872 (2011). 